\title{
Remote Cerebellar Hemorrhage Associated With Intra-Operative Cerebrospinal Fluid Leak: A Report of Two Rare Case Presentations and Review of the Literature
}

\author{
Long $\mathrm{Di}^{1}{ }^{\text {, Grace Wei }}{ }^{1}$, Daniel G. Eichberg ${ }^{1}$, Ricardo J. Komotar ${ }^{1,2}$, Michael Ivan ${ }^{1,} 2$ \\ 1. Neurological Surgery, University of Miami Miller School of Medicine, Miami, USA 2. Neurological Surgery, Sylvester \\ Comprehensive Cancer Center, Miami, USA
}

Corresponding author: Long Di, longdi1996@gmail.com

\begin{abstract}
Remote cerebellar hemorrhage (RCH) is a rare complication following cranial or spinal neurosurgical procedures. Traditionally, RCH has been associated with frontal or frontotemporal craniotomy with supine patient positioning. Though the exact etiology is unknown, theories have described patient positioning and excessive cerebrospinal fluid (CSF) drainage intra-operatively as contributing factors to cerebellar displacement (cerebellar sag), obstruction of venous flow, and pathogenesis of RCH.
\end{abstract}

We report two cases of RCH following a prone, suboccipital craniotomy-C1 laminectomy and a temporal burr hole evacuation of a subdural hygroma. In each case, a large volume of CSF was rapidly evacuated intraoperatively. To the best of our knowledge, both instances represent relatively rare settings for RCH. Additionally, we conducted a comprehensive literature review of PubMed, EMBASE, and Web of Science for all cases of RCH in which peri-operative CSF leakage was explicitly detailed.

Although RCH is thought to be a rare complication of frontotemporal and frontal craniotomies, this case report signifies that RCH may occur in the setting of sub-occipital craniotomy or even after minimally invasive burr hole procedures. For these procedures, careful symptomatic monitoring and follow-up imaging remain essential in diagnosis. Controlled CSF drainage may be useful in mediating dramatic alterations in intracranial pressure (ICP) and cerebellar sag contributing to RCH.

Received 08/09/2020 Review began 11/19/2020 Review ended 12/06/2020 Published 12/14/2020

○) Copyright 2020 Di et al. This is an open access article distributed under the terms of the Creative Commons Attribution License CC-BY 4.0., which permits unrestricted use, distribution, and reproduction in any medium, provided the original author and source are credited.
Categories: Neurosurgery

Keywords: remote cerebellar hemorrhage, rch, cerebrospinal fluid, suboccipital, burr hole, subdural hygroma

\section{Introduction}

Remote cerebellar hemorrhage $(\mathrm{RCH})$ is a rare intracerebral hemorrhage isolated from surgical sites following cranial or spinal procedures that may result in significant peri-operative neurologic morbidity and mortality [1]. Diagnosis involves detection of neurologic symptoms, commonly impaired consciousness, followed by identification of a "zebra sign" on axial head CT [1]. The pathogenesis and pathophysiology of $\mathrm{RCH}$ remain puzzling and several mechanisms explaining its etiology have been described, including cerebrospinal fluid (CSF) egress causing “cerebellar sag” and kinking of posterior venous sinuses [2]. Interestingly, $\mathrm{RCH}$ seems to occur most frequently following frontal or frontotemporal craniotomies contralateral to the side of RCH with supine patient positioning [3]. We report two rare presentations of RCH following sub-occipital craniotomy for a foramen magnum meningioma and burr hole evacuation of a temporal cystic hygroma. To our knowledge, this is one of the first reports of RCH following prone, suboccipital craniotomy, and minimally invasive burr hole procedure for hygroma evacuation. In both cases, rapid and extensive CSF evacuation occurred. Additionally, we present a literature review of all reported $\mathrm{RCH}$ cases following craniotomy or spine procedure with explicitly stated peri-operative CSF leakage.

\section{Case Presentation}

\section{Case 1}

A 55-year-old female presented to our clinic with several months history of right-sided facial numbness and left upper extremity numbness and tingling that progressed to the right upper extremity. She was referred by an outside neurologist following MRI that demonstrated a large, right-sided foramen magnum lesion compressing the spinal cord and brainstem. Imaging revealed a homogenously enhancing, extramedullary, intradural mass extending from the level of the foramen magnum to the mid-C2 vertebral body with an associated dural tail (Figures 1A, 1B). 


\section{Cureus}
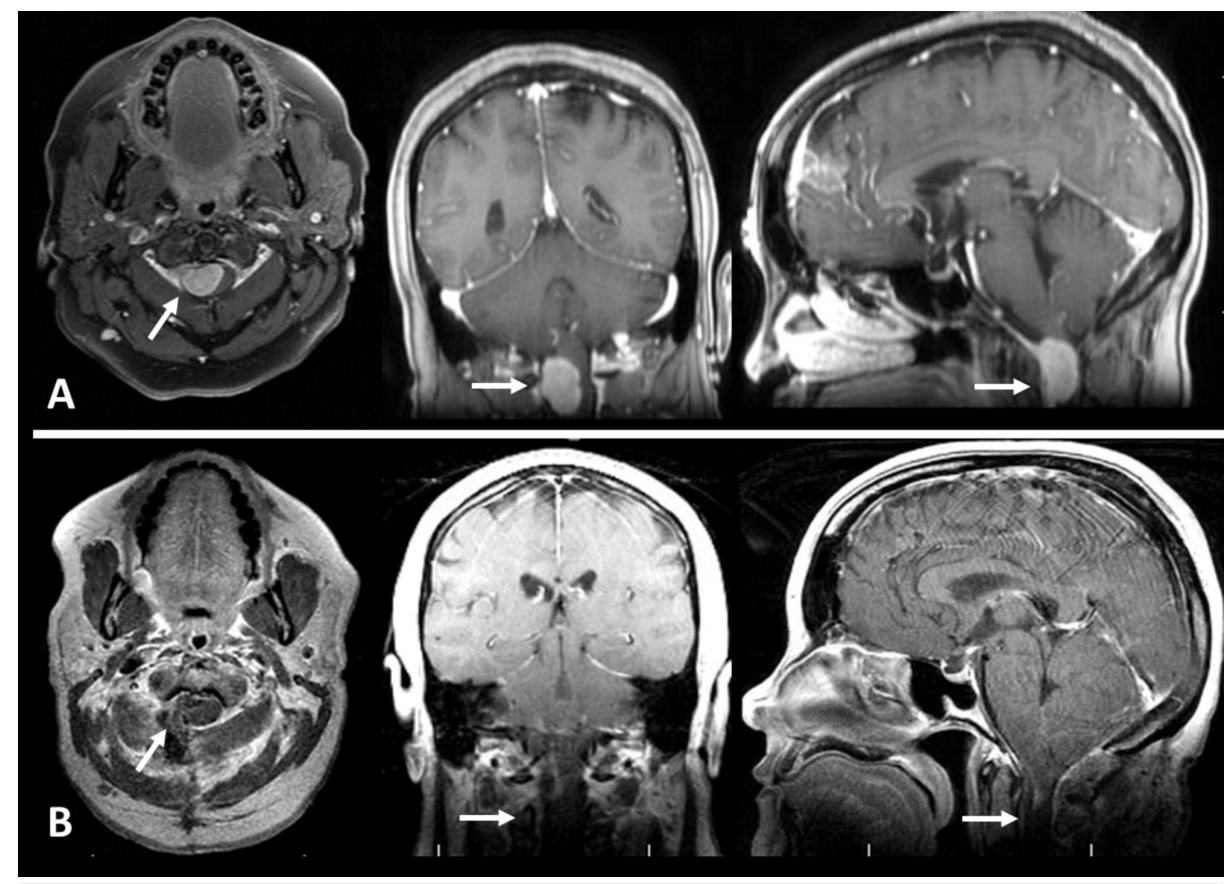

FIGURE 1: Pre-operative and post-operative T1 post-gadolinium contrast (T1C+) MRIs of a foramen magnum meningioma resected via sub-occipital craniotomy.

(A) Pre-operative axial, coronal, and sagittal T1C+ images. (B) Post-operative images following gross total resection of meningioma.

Significant mass effect, compression, and displacement of the corticomedullary junction and upper cervical cord were identified. A working diagnosis of foramen magnum meningioma was made and the patient was scheduled for resection of the lesion. A sub-occipital craniotomy and C1-C2 laminectomy were performed with the patient in the prone position. During the exposure, standard arachnoid dissection facilitated CSF egress permitting a maximal safe resection of the tumor with minimal cerebellar retraction. On a postoperative day (POD) one, the patient developed nausea, vomiting, and positional headache exacerbated while lying flat. CT showed an interval increase in ventricular size with new cerebellar hyperdensity concerning hemorrhage and effacement of the fourth ventricle (Figure 2). 


\section{Cureus}

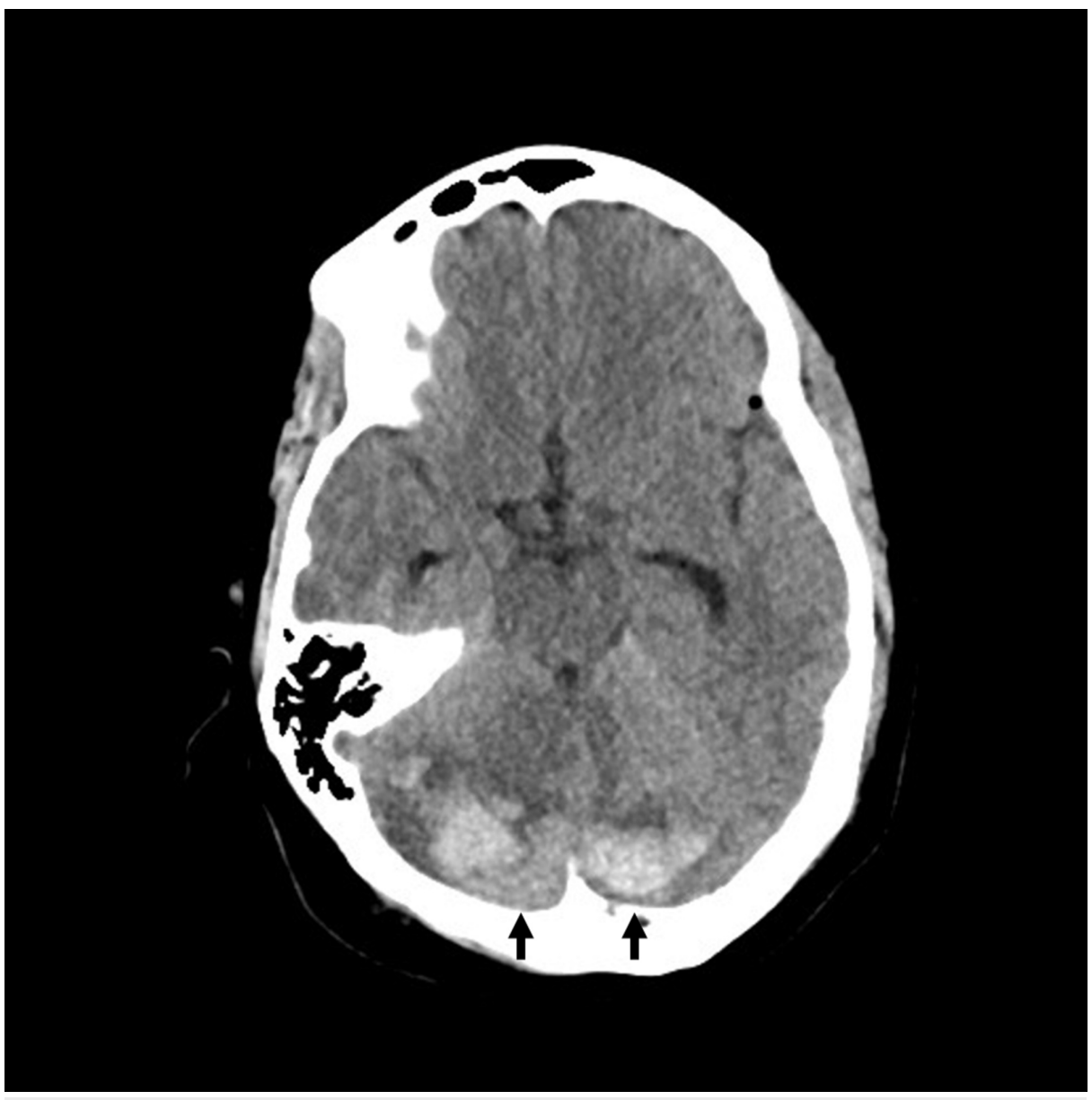

FIGURE 2: Axial CT indicating post-operative day one bilateral RCH in the superior cerebellum.

$\mathrm{RCH}$ : remote cerebellar hemorrhage

A diagnosis of acute obstructive hydrocephalus was made, and an emergency right frontal external ventricular drain (EVD) was placed. The RCH stabilized, hydrocephalus resolved, and EVD was removed on POD 10; the patient was discharged on POD 14. At one-month follow-up, the patient displayed a complete resolution of symptoms following physical rehabilitation; strength was $5 / 5$ in bilateral upper and lower extremities with a Karnofsky Performance Status (KPS) of 90.

\section{Case 2}

A 79-year-old man with a history of hypertension, diabetes, hyperlipidemia, and aspirin use presented to our clinic with a three-day history of worsening generalized weakness and headache. The patient denied any symptoms other than weakness and slight tremor. Prior head CT displayed a large right-sided, hollow hemispheric hygroma with approximately $1 \mathrm{~cm}$ midline shift. The patient denied prior head trauma and no other focal neurologic deficits were observed. After five days of aspirin cessation, the patient underwent hygroma evacuation. Two burr holes were made and, following the dural opening, high-pressure CSF was immediately evacuated (Figures $3 A, 3 B$ ).

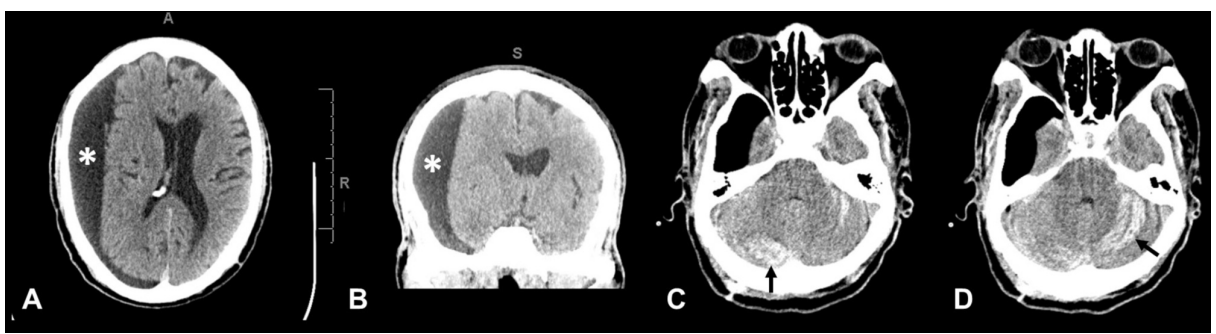

FIGURE 3: Case of bilateral RCH following burr hole evacuation of a 
right cystic hygroma.

(A \& B) Large right holohemispheric subdural hygroma measuring $2.8 \mathrm{~cm}$ in widest diameter with right hemispheric sulcal effacement and $10 \mathrm{~mm}$ of leftward midline shift. (C \& D) s/p right-sided burr holes and placement of a subdural drain noted on postop CT were new bilateral cerebellar hemorrhages.

${ }^{\star}$ Right subdural cystic hygroma.

$\mathrm{RCH}$ : remote cerebellar hemorrhage

A Jackson-Pratt (JP) drain was placed over the posterior burr hole followed by closure. The patient awoke on POD one able to follow commands but over subsequent hours, decompensated and had a tonic-clonic seizure. Head CT revealed a new cerebellar hemorrhage and the patient was taken for emergent suboccipital decompression (Figures 3C, 3D). On POD nine, the patient was able to open his eyes, weakly withdrew bilateral upper extremities to pain, and moved bilateral lower extremities spontaneously. Unfortunately, the patient's condition continued to deteriorate. On POD 27, the patient had not recovered neurologically, remaining intubated and dependent on tube feeding; the decision to pursue palliative care was made and the patient was discharged to a nursing home.

\section{Discussion}

A comprehensive literature review was performed in PubMed, EMBASE, and Web of Science databases to identify RCH cases with perioperative CSF leakage. Keywords included: remote, cerebellar, and hemorrhage. All abstracts were reviewed, and relevant articles were collected using the following inclusion and exclusion criteria. All articles in the English language presenting cases of RCH with perioperative CSF leakage were included. Review articles, letters and commentary, and cases without specific mention of perioperative CSF loss were excluded.

Including our own, twelve cases of RCH following craniotomy with peri-operative CSF leakage were identified [4-10]. The average patient age was 58.25 years. Nine patients were male and three were female. The majority of cases were pterional craniotomies (4) and temporal (3). In cases providing positioning detail, all patients were placed supine. Post-operative clinical findings included altered mental status (7), nausea, dysarthria, seizure, hemineglect, hemiplegia, headache, and ataxia; one case was identified incidentally on follow-up imaging. On imaging, bilateral and unilateral RCH were identified in eight and four patients, respectively. Typical "zebra" hemorrhage patterns were seen in most cases (Figure 3D). In addition, 58.3\% of patients exhibited complete symptom resolution following decompression (7) with a motor deficit (2) and death (2) in $16.7 \%$ of patients, respectively. These cases are summarized in Table 1. 


\section{Cureus}

\begin{tabular}{|c|c|c|c|c|c|c|c|c|c|c|c|}
\hline$\#$ & Reference & Age & Sex & Side & $\begin{array}{l}\text { Location of } \\
\text { Craniotomy }\end{array}$ & $\begin{array}{l}\text { Position of } \\
\text { Patient }\end{array}$ & Clinical Findings & $\begin{array}{l}\text { Post- } \\
\text { Operative } \\
\text { Hemorrhage }\end{array}$ & $\begin{array}{l}\text { Follow- } \\
\text { Up } \\
\text { (months) }\end{array}$ & Outcome & $\begin{array}{l}\text { Proposed } \\
\text { Mechanism }\end{array}$ \\
\hline 1 & $\begin{array}{l}\text { Current study } \\
\text { (Case 1) }\end{array}$ & 55 & $\mathrm{~F}$ & Mi & Suboccipital & Prone & Nausea & Bilateral RCH & 1 & Complete resolution & $\begin{array}{l}\text { Excessive } \\
\text { CSF loss }\end{array}$ \\
\hline 2 & $\begin{array}{l}\text { Current study } \\
\text { (Case 2) }\end{array}$ & 79 & $\mathrm{M}$ & $\mathrm{R}$ & $\begin{array}{l}\text { Temporal (burr } \\
\text { hole) }\end{array}$ & Prone & Tonic clonic seizure & Bilateral RCH & 0.3 & Coma & $\begin{array}{l}\text { Excessive } \\
\text { CSF loss }\end{array}$ \\
\hline 3 & $\begin{array}{l}\text { Caldeira et al., } \\
2017[4]\end{array}$ & 70 & $\mathrm{M}$ & - & Frontal & Supine & None & Unilateral RCH & 0.5 & Complete resolution & $\begin{array}{l}\text { Excessive } \\
\text { CSF loss }\end{array}$ \\
\hline 4 & $\begin{array}{l}\text { Koh et al., } 2017 \\
\text { [6] }\end{array}$ & 62 & M & L & Pterional & - & Altered mental status & Bilateral RCH & 0.5 & Death & $\begin{array}{l}\text { Excessive } \\
\text { CSF loss }\end{array}$ \\
\hline 5 & Li et al., 2013 [7] & 51 & $\mathrm{M}$ & L & Pterional & - & Altered mental status & Unilateral $\mathrm{RCH}$ & 3 & Complete resolution & $\begin{array}{l}\text { Excessive } \\
\text { CSF loss }\end{array}$ \\
\hline 6 & Li et al., 2013 [7] & 67 & $\mathrm{~F}$ & L & Pterional & - & Altered mental status & Bilateral RCH & 3 & Complete resolution & $\begin{array}{l}\text { Excessive } \\
\text { CSF loss }\end{array}$ \\
\hline 7 & $\begin{array}{l}\text { Ziyal et al., } 2012 \\
{[10]}\end{array}$ & 30 & $\mathrm{M}$ & L & Temporal & - & Headache, ataxia & Unilateral $\mathrm{RCH}$ & 0.25 & Complete resolution & $\begin{array}{l}\text { Excessive } \\
\text { CSF loss }\end{array}$ \\
\hline 8 & $\begin{array}{l}\text { De Ribaupierre } \\
\text { et al., } 2004 \text { [5] }\end{array}$ & 8 & M & $\mathrm{L}$ & Periinsular & $\begin{array}{l}\text { Supine; head } \\
\text { rotated right }\end{array}$ & Altered mental status & Bilateral $\mathrm{RCH}$ & 25 & Complete resolution & $\begin{array}{l}\text { Excessive } \\
\text { CSF loss }\end{array}$ \\
\hline 9 & $\begin{array}{l}\text { Maruyama et al., } \\
2004 \text { [8] }\end{array}$ & 83 & $M$ & L & Frontotemporal & $\begin{array}{l}\text { Supine; head } \\
\text { rotated right }\end{array}$ & Dysarthria & Bilateral RCH & 0.5 & Complete resolution & $\begin{array}{l}\text { Excessive } \\
\text { CSF loss }\end{array}$ \\
\hline 10 & $\begin{array}{l}\text { Siu et al., } 2003 \\
\text { [9] }\end{array}$ & 54 & M & L & Pterional & $\begin{array}{l}\text { Head rotated } \\
\text { right }\end{array}$ & $\begin{array}{l}\text { Altered mental status, } \\
\text { hemiplegia, hemineglect }\end{array}$ & Bilateral $\mathrm{RCH}$ & 1 & $\begin{array}{l}\text { Upper limb and facial } \\
\text { paresis, dysarthria }\end{array}$ & $\begin{array}{l}\text { Excessive } \\
\text { CSF loss }\end{array}$ \\
\hline 11 & $\begin{array}{l}\text { Siu and } \\
\text { Chandran, } 2003 \\
\text { [9] }\end{array}$ & 64 & $\mathrm{M}$ & $\mathrm{R}$ & Temporal & $\begin{array}{l}\text { Head tilted } \\
\text { left }\end{array}$ & Altered mental status & Bilateral RCH & 0.3 & Death & $\begin{array}{l}\text { Excessive } \\
\text { CSF loss }\end{array}$ \\
\hline 12 & $\begin{array}{l}\text { Chandran, } 2003 \\
\text { [9] }\end{array}$ & 76 & $\mathrm{~F}$ & $\mathrm{R}$ & Parietotemporal & Lateral & Altered mental status & Unilateral RCH & 2 & Upper limb weakness & $\begin{array}{l}\text { Excessive } \\
\text { CSF loss }\end{array}$ \\
\hline
\end{tabular}

\section{TABLE 1: Characteristics of Cranial Cases}

$\mathrm{RCH}$ : remote cerebellar hemorrhage; M: male; F: female; L: left; R: right; Mi: midline

Seven cases of RCH following spinal surgery with peri-operative CSF leak were identified [11-16]. The average patient age was 61.57 years. Three patients were male and four were female. All cases were lumbar surgeries (7). Patient body positioning on all available cases (4) was prone. Peri-operative CSF leaks following intradural lesions were observed in $85.7 \%$ of patients (6), with CSF leaks after extradural pathology and dural tear observed in only $14.3 \%$ of patients (1). Post-operative clinical findings included altered mental status (6), nausea, emesis, dysarthria, seizure, headache, and diplopia. On imaging, bilateral and unilateral RCH was identified in six and one patient(s), respectively. Long-term patient outcomes included complete symptom resolution in $57.1 \%$ of patients (4), with a motor deficit in $28.6 \%$ (2) and death in $14.3 \%$ of patients (1). Table 2 represents all reports of RCH following spinal surgery included in this review; data for both cranial and spinal cases are statistically summarized in Tables 3,4 , respectively. 


\section{Cureus}

\begin{tabular}{|c|c|c|c|c|c|c|c|c|c|c|c|}
\hline \# & Reference & Age & Sex & $\begin{array}{l}\text { Location of } \\
\text { Spine Surgery }\end{array}$ & $\begin{array}{l}\text { Position } \\
\text { of Patient }\end{array}$ & $\begin{array}{l}\text { Presence of } \\
\text { Dural Tear }\end{array}$ & Clinical Findings & $\begin{array}{l}\text { Post-Operative } \\
\text { Hemorrhage }\end{array}$ & $\begin{array}{l}\text { Follow-Up } \\
\text { (months) }\end{array}$ & Outcome & $\begin{array}{l}\text { Proposed } \\
\text { Mechanism }\end{array}$ \\
\hline 1 & $\begin{array}{l}\text { Khalatbari et al, } \\
2012 \text { [13] }\end{array}$ & 53 & M & Lumbar & Prone & No & $\begin{array}{l}\text { Headache, emesis, altered } \\
\text { mental status }\end{array}$ & Bilateral RCH & 3 & $\begin{array}{l}\text { Complete } \\
\text { Resolution }\end{array}$ & $\begin{array}{l}\text { Excessive } \\
\text { CSF loss }\end{array}$ \\
\hline 2 & $\begin{array}{l}\text { Khalatbari et } \\
\text { al., } 2012[13]\end{array}$ & 75 & M & Lumbar & Prone & Yes & Altered mental status & Bilateral RCH & 0.5 & Death & $\begin{array}{l}\text { Excessive } \\
\text { CSF loss }\end{array}$ \\
\hline 3 & $\begin{array}{l}\text { Lee et al., } 2012 \\
\text { [15] }\end{array}$ & 63 & $\mathrm{~F}$ & Lumbar & - & Yes & $\begin{array}{l}\text { Generalized tonic-clonic } \\
\text { seizures, altered mental status }\end{array}$ & Bilateral RCH & 0.4 & $\begin{array}{l}\text { Complete } \\
\text { Resolution }\end{array}$ & $\begin{array}{l}\text { Excessive } \\
\text { CSF loss }\end{array}$ \\
\hline 4 & $\begin{array}{l}\text { Gul et al., } 2010 \\
\text { [12] }\end{array}$ & 64 & $\mathrm{~F}$ & Lumbar & Prone & Yes & Diplopia, altered mental status & Unilateral $\mathrm{RCH}$ & 0.7 & $\begin{array}{l}\text { Gait ataxia, } \\
\text { left foot drop }\end{array}$ & $\begin{array}{l}\text { Excessive } \\
\text { CSF loss }\end{array}$ \\
\hline 5 & $\begin{array}{l}\text { Nam et al., } \\
2009 \text { [16] }\end{array}$ & 61 & M & Lumbar & - & Yes & $\begin{array}{l}\text { Headache, nausea, altered } \\
\text { mental status }\end{array}$ & Bilateral RCH & 1.5 & $\begin{array}{l}\text { Mild } \\
\text { cerebellar } \\
\text { signs }\end{array}$ & $\begin{array}{l}\text { Excessive } \\
\text { CSF loss }\end{array}$ \\
\hline 6 & $\begin{array}{l}\text { Calisaneller et } \\
\text { al., } 2007 \text { [11] }\end{array}$ & 67 & $\mathrm{~F}$ & Lumbar & - & Yes & $\begin{array}{l}\text { Headache, gait ataxia, } \\
\text { unsteadiness }\end{array}$ & Bilateral RCH & - & $\begin{array}{l}\text { Complete } \\
\text { Resolution }\end{array}$ & $\begin{array}{l}\text { Excessive } \\
\text { CSF loss }\end{array}$ \\
\hline 7 & $\begin{array}{l}\text { Konya et al., } \\
2006[14]\end{array}$ & 48 & $\mathrm{~F}$ & Lumbar & Prone & Yes & $\begin{array}{l}\text { Headache, dysarthria, emesis, } \\
\text { altered mental status }\end{array}$ & Bilateral RCH & 6 & $\begin{array}{l}\text { Complete } \\
\text { Resolution }\end{array}$ & $\begin{array}{l}\text { Excessive } \\
\text { CSF loss }\end{array}$ \\
\hline
\end{tabular}

TABLE 2: Characteristics of Spinal Cases

$\mathrm{RCH}$ : remote cerebellar hemorrhage; M: male; F: female 


\section{Cureus}

Characteristic

Total Patients

Male

Female

Age (mean $\pm S D)$

Craniotomy Side

Left

Right

Midline

Craniotomy Location

Pterional

Temporal

Other

Presentation

Altered Mental Status

Other

Imaging

Bilateral

Unilateral

Outcome

Complete Resolution

Motor Deficit

Death

Recovering
Total (\%)

12

9 (75)

2 (25)

$58.25 \pm 21.37$

7 (58.3)

3 (25)

1 (8.3)

4 (33.3)

3 (25)

5 (41.7)

7 (58.3)

5 (41.7)

8 (66.7)

4 (33.3)

7 (58.3)

2 (16.7)

2 (16.7)

1 (8.3)

TABLE 3: Summary of Cranial Cases

SD: standard deviation 


\section{Cureus}

\begin{tabular}{|c|c|}
\hline Characteristic & Total (\%) \\
\hline Total Patients & 7 \\
\hline Male & $3(42.9)$ \\
\hline Female & $4(57.1)$ \\
\hline Age (mean $\pm S D)$ & $61.57 \pm 8.9$ \\
\hline \multicolumn{2}{|l|}{ Spinal Surgery Level } \\
\hline Lumbar & $7(100)$ \\
\hline \multicolumn{2}{|l|}{ Presence of Dural Tear } \\
\hline Yes & $6(85.7)$ \\
\hline No & $1(14.3)$ \\
\hline \multicolumn{2}{|l|}{ Presentation } \\
\hline Altered Mental Status & $6(85.7)$ \\
\hline Other & $1(14.3)$ \\
\hline \multicolumn{2}{|l|}{ Imaging } \\
\hline Bilateral & $6(85.7)$ \\
\hline Unilateral & 1 (14.3) \\
\hline \multicolumn{2}{|l|}{ Outcome } \\
\hline Complete Resolution & $4(57.1)$ \\
\hline Motor Deficit & $2(28.6)$ \\
\hline Death & $1(14.3)$ \\
\hline
\end{tabular}

\section{TABLE 4: Summary of Spinal Cases}

Remote cerebellar hemorrhage is a rare complication following cranial and spinal surgeries with an estimated incidence of $0.08-0.6 \%$ [1]. RCH likely occurs due to rapid perioperative excess CSF loss leading to post-operative hemorrhagic venous infarction. Substantial CSF loss may result in "cerebellar sag," with cerebellar shift downward; subsequent stretching of cerebellar short bridging veins may cause transient occlusion, leading to venous infarction and hemorrhage [3]. It remains unclear if RCH is precipitated perioperatively or post-operatively, though most cases are identified immediately following surgery [3]. Indeed, both of our cases presented with neurologic symptoms and axial CT indicating RCH on a post-operative day one. Thus, post-operative monitoring and follow-up imaging may be essential in diagnosis and treatment with suboccipital decompression - even after procedures not traditionally associated with RCH.

Several symptoms have been described in patients who develop RCH following supratentorial craniotomy including altered level of consciousness, motor deficits, gait ataxia, and seizures [3]. Concern for edema and mass effect in the posterior fossa on the 4th ventricle can lead to sudden hydrocephalus and needs to be carefully monitored and urgently treated if it develops [1]. RCH may also present asymptomatically, and thus many patients with RCH proceed undiagnosed [3]. In these cases, follow-up imaging is essential to early detection. In a systematic review by Sturiale et al., symptomatic diagnosis of post-craniotomy RCH was made in $63 \%$ of reported cases and asymptomatic diagnosis in $37 \%$ of cases found incidentally on postoperative imaging [1]. Conversely, symptomatic diagnosis of post-spinal surgery RCH was made in $100 \%$ of cases, as no post-operative imaging was performed without complaint of neurologic symptoms [17]. Overall mortality in our reviewed cases were $16.7 \%$ and $14.3 \%$ for post-craniotomy and post-spinal surgery, respectively.

Interestingly, our review yielded only one asymptomatic case identified incidentally on follow-up imaging. It is possible minor intra-operative or post-operative CSF leaks present with milder symptoms due to less dramatic intracranial pressure changes. Konig et al. identified higher frequencies of RCH following resection of large supratentorial tumors and hypothesized that resection of larger masses confer greater reduction of 
intracranial pressure (ICP) and increased transmural venous pressure, increasing RCH risk [18]. However, it is curious then why RCH is not common after routine lumbar drain (LD) or EVD placement following cranial surgery or ventriculoperitoneal (VP) shunt placement for hydrocephalus. We hypothesize that rapid rates of large volumes of CSF leakage, and thus rate of ICP decline, combined with unique anatomical configurations of venous drainage, contribute to post-operative $\mathrm{RCH}$ and explain the lack of $\mathrm{RCH}$ reports following controlled CSF drainage.

The role of patient positioning in RCH pathogenesis is uncertain. In craniotomy cases with position reported, patients were commonly placed supine with the head rotated opposite the craniotomy [9]. Interestingly, in both of our cases, hemorrhage occurred in the cerebellar hemisphere contralateral to the direction of head rotation. This corroborates Papanastassiou, Adams, and Chir's hypothesis that hemorrhage preferentially occurs contralateral to the craniotomy as the contralateral cerebellar hemisphere is directed posteriorly to abut and kink the transverse sinus following CSF leakage [2]. Cerebellar movement opposite the craniotomy site may also explain the higher occurrence of RCH in frontal, frontotemporal, or pterional craniotomies [4,6-10]. Additionally, "cerebellar sag" and compression of posterior venous sinuses may be further exacerbated by gravity with supine positioning. This underscores the rarity of our case presentation. Our cases are among the first to report RCH occurrence following suboccipital craniotomies in the prone position. With prone, suboccipital craniotomy, we postulate anterior cerebellar displacement is causing compression of anterior cerebellar veins, rather than compression of the transverse or sigmoid sinuses. Notably, the role of patient positioning in RCH following spinal surgeries has been insignificant $[11,13,14]$. Interestingly, all cases of RCH following spine surgery included in our review occurred following surgery at the lumbar level; this is consistent with prior literature showing the incidence of RCH is highest in surgeries involving lumbosacral segments compared to cervical and thoracic [17].

Our study highlights the importance of avoiding rapid excessive CSF loss during surgery, to reduce the risk of RCH peri-operative complications. The use of controlled CSF drainage techniques, including small controlled dural openings, provides favorable strategies to regulate peri-operative CSF drainage rates. If large losses of CSF are observed, patients should be carefully monitored and imaged post-operatively. Placing patients in reverse Trendelenburg can be performed if there is a concern for RCH after high-risk procedures, although no data supporting this method has been shown. For symptomatic patients with altered mental status and reduced consciousness, RCH secondary to hemorrhagic venous infarction should be suspected.

Our cases illustrate that RCH is not limited to supratentorial craniotomies. Our case following burr hole surgery represents a rare neurosurgical setting for post-operative RCH. To our knowledge, only two previous cases of RCH following burr hole evacuation of subdural hematomas have been described $[19,20]$. The proposed pathophysiology remains similar, massive and rapid evacuation of a space-occupying lesion resulting in a drastic decrease in ICP. These reports signify that post-operative RCH is not limited to craniotomies; careful monitoring remains essential in other procedures involving rapid and large volume evacuation or reduction in ICP. Thus, to avoid an overly rapid rate of CSF drainage following burr hole subdural hygroma evacuation, we recommend placing JP bulb to gravity suction rather than self-suction and keeping the patient supine post-operatively.

\section{Conclusions}

Although RCH is largely considered a frontotemporal and frontal craniotomy complication, we report the first known case of RCH following suboccipital craniotomy. Additionally, we report one of the first cases of RCH following burr holes for subdural hygroma evacuation, demonstrating the risk of RCH even after lessinvasive procedures. Although traditional descriptions of RCH etiology detail intra-operative over drainage of CSF, we hypothesize it is the rate of CSF drainage, rather than volume, that contributes to RCH pathogenesis. Controlled CSF drainage may prevent this occurrence from happening. Similarly, after burr holes for subdural hygromas, it may be wise to place JP drains to gravity rather than bulb suction.

\section{Additional Information}

\section{Disclosures}

Human subjects: Consent was obtained by all participants in this study. University of Miami Institutional Review Board issued approval 20160437. The consent process was waived as this was a retrospective study stripped of all identifying information. Conflicts of interest: In compliance with the ICMJE uniform disclosure form, all authors declare the following: Payment/services info: All authors have declared that no financial support was received from any organization for the submitted work. Financial relationships: Daniel G. Eichberg, MD declare(s) a grant from National Cancer Institute. Dr. Daniel Eichberg is supported by a grant from the National Cancer Institute (NCI; T32 CA 211034). No federal funds or funds from nongovernmental sources were used to fund the project. The content is solely the responsibility of the authors and does not necessarily represent the official views of the National Institutes of Health. Michael E. Ivan, MD, MBS declare(s) a grant from University of Miami, Magic Leap. Dr. Michael Ivan holds a grant from the office of the Provost at the University of Miami in association with Magic Leap (Plantation, Florida) augmented reality applications development for Neurosurgery. . Michael E. Ivan, MD, MBS declare(s) personal fees from Medtronic, NX Development Corporation. Dr. Michael Ivan reports being a consultant to 
and receiving research funding from Medtronic and the NX Development Corporation. . Other relationships: All authors have declared that there are no other relationships or activities that could appear to have influenced the submitted work.

\section{References}

1. Sturiale CL, Rossetto M, Ermani M, et al.: Remote cerebellar hemorrhage after supratentorial procedures (part 1): a systematic review. Neurosurg Rev. 2016, 39:565-573. 10.1007/s10143-015-0691-6

2. Papanastassiou V, Adams C: Contralateral cerebellar hemorrhagic infarction after pterional craniotomy: report of five cases and review of the literature. Neurosurgery. 1996, 39:841-851. 10.1097/00006123199610000-00040

3. Friedman JA, Piepgras DG, Duke DA, et al.: Remote cerebellar hemorrhage after supratentorial surgery. Neurosurgery. 2001, 49:1327-1340. 10.1097/00006123-200112000-00008

4. Caldeira I, Lavrador J, Basílio G, Sousa R, Reimão S: Remote cerebellar haemorrhage after placement of an external ventricular drainage for acute hydrocephalus: a case report. Neurochirurgie. 2017, 63:28-30. 10.1016/j.neuchi.2016.11.109

5. de Ribaupierre S, Villemure JG, Chalaron M, Cotting J, Pollo C: Contralateral frontal and cerebellar haemorrhages after peri-insular hemispherotomy. Acta Neurochir (Wien). 2004, 146:743-744. 10.1007/s00701-004-0255-y

6. Koh E-J, Park J-S: Fatal remote cerebellar hemorrhage after supratentorial unruptured aneurysm surgery in patient with previous cerebellar infarction. Medicine (Baltimore). 2017, 96:5938-5940. 10.1097/MD.0000000000005938

7. Li D, Fu C, Xu D, Sun L, Yu W, Zhao C: Remote peritentorial hemorrhage complicating supratentorial aneurysmal surgery: a report of three cases and literature review. Acta Neurochir (Wien). 2013, 155:271-276. 10.1007/s00701-012-1540-9

8. Maruyama T, Ishii K, Isono M, Abe T, Fujiki M, Kobayashi H: Remote cerebellar hemorrhage following supratentorial craniotomy--case report. Neurol Med Chir (Tokyo). 2004, 44:294-297. 10.2176/nmc.44.294

9. Siu TLT, Chandran KN: Cerebellar haemorrhage following supratentorial craniotomy. J Clin Neurosci. 2003, 10:378-384. 10.1016/S0967-5868(03)00024-9

10. Ziyal I, Bilginer B, Yavuz K, Turk C, Ozgur C, Benli K: Does ventricular opening promote remote cerebellar haemorrhage?. Turk Neurosurg. 2012, 22:102-104. 10.5137/1019-5149.JTN.3063-10.5

11. Calisaneller T, Yilmaz C, Ozger O, Caner H, Altinors N: Remote cerebellar haemorrhage after spinal surgery . Can J Neurol Sci. 2007, 34:483-484. 10.1017/s031716710000740x

12. Gul S, Kalayci M, Acikgoz B: A rare complication of spinal surgery: cerebellar hemorrhage . Turk Neurosurg. 2010, 20:413-417. 10.5137/1019-5149.JTN.2283-09.2

13. Khalatbari MR, Khalatbari I, Moharamzad Y: Intracranial hemorrhage following lumbar spine surgery. Eur Spine J. 2012, 21:2091-2096. 10.1007/s00586-012-2187-1

14. Konya D, Ozgen S, Pamir MN: Cerebellar hemorrhage after spinal surgery: case report and review of the literature. Eur Spine J. 2006, 15:95-99. 10.1007/s00586-005-0987-2

15. Lee H-Y, Kim S-H, So K-Y: Seizure and delayed emergence from anesthesia resulting from remote cerebellar hemorrhage after lumbar spine surgery -A case report-. Korean J Anesthesiol. 2012, 63:270-273. 10.4097/kjae.2012.63.3.270

16. Nam TK, Park SW, Min BK, Hwang SN: Remote cerebellar hemorrhage after lumbar spinal surgery. J Korean Neurosurg Soc. 2009, 46:501-504. 10.3340/jkns.2009.46.5.501

17. Sturiale CL, Rossetto M, Ermani M, et al.: Remote cerebellar hemorrhage after spinal procedures (part 2): a systematic review. Neurosurg Rev. 2016, 39:369-376. 10.1007/s10143-015-0673-8

18. Konig A, Laas R, Herrmann HD: Cerebellar haemorrhage as a complication after supratentorial craniotomy . Acta Neurochir (Wien). 1987, 88:104-108. 10.1007/bf01404145

19. Moser M, Hildebrandt G: Remote cerebellar hemorrhage after supratentorial burr-hole trepanation for unilateral chronic subdural hematoma: case report. NMC Case Rep J. 2015, 2:114-117. 10.2176/nmccrj.cr.2014-0377

20. Kollatos C, Konstantinou D, Raftopoulos S, et al.: Cerebellar hemorrhage after supratentorial burr hole drainage of a chronic subdural hematoma. Hippokratia. 2011, 15:370-372. 